\title{
'Asi - The presence of the unseen
}

\author{
Keywords \\ 'Asi, Co-creation, Creativity, Faiva, Oceanic.
}

This paper considers an indigenous, methodological framework developed for my doctoral thesis, 'Asi: The Presence of the Unseen. Defined as 'Ngatu' the framework employs the heliaki (metaphor) of women's collective crafting of indigenous fabric, to structure an artistic research project. Ngatu is cloth made from the bark of the paper mulberry tree. Used for floor mats, bedding, clothing and room dividers it is also often given as a gift at weddings, funerals and formal presentations. Ngatu is considered one of Oceania's distinctive art forms and processes. Within the study, the position of the researcher is both a creator of artistic work and a reflector on the experience and practices of other collaborators. The Ngatu framework enables a practice-led inquiry that is underpinned by indigenous principles: uouongataha (the pursuit of harmony), mālie/māfana (warmth and beauty) and anga fakatōkilalo (being open to learning). Guided by these values, the methodology employs five distinct phases: TŌ (gestation); $T \bar{A}$ (harvesting knowledge); NGAOHI / TUTU (preparing and expanding ideas); HOKO/ KOKA'ANGA (harmonious composition), and FOAKI (presentation). The Ngatu methodology may be seen in the light of a significant discussion in 2019, where a gathering of Oceanic scholars considered a proliferation of Indigenous models of inquiry that had been developed by Pacific researchers outside of conventional Western research paradigms. Although much of the discussion focused on research emanating from Health and the Social Sciences, the use of heliaki to describe methodological approaches to artistic inquiry also has a discernible history in doctoral theses in Aotearoa/New Zealand (Pouwhare, 2020; Toluta'u, 2015; Tupou, 2018; Vea, 2015). The Ngatu methodological framework was applied to the question, "What occurs when young Oceanic people work together artistically in a group, drawing on values from their cultural heritage to create meaningful faiva (artistic performances)?" In posing this question, the thesis sought to understand how, 'asi (the spirit of the unseen), might operate as an empowering agency for endeavour and belonging. As such, the study proposed that 'asi which is conventionally identified at the peak of artistic performance, might be also discernible before and after such an event, and resource the energy of artistic practice as a whole. The Ngatu methodology was applied to two bodies of work. The first was a co-created project called Lila. This was developed by a team of secondary school students who produced a contemporary faiva for presentation in 2019. This case study was used in conjunction with interviews from contemporary Oceanic youth leaders, reflecting on the nature and agency of 'asi, as it appears in their artistic workshops with young people. The second work was a performance called FAIVA | FAI VĀ. This was the researcher's artistic response to the witnessed nature of 'asi. The performance integrated spoken word poetry, sound, illustration and video design. 